\title{
Preface
}

\section{Knee Multiligament Injury}

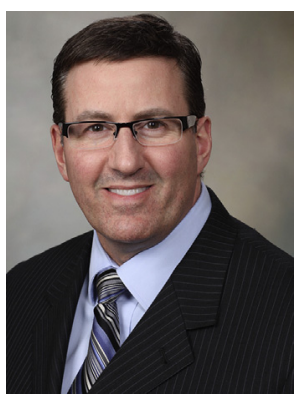

Bruce A. Levy, MD

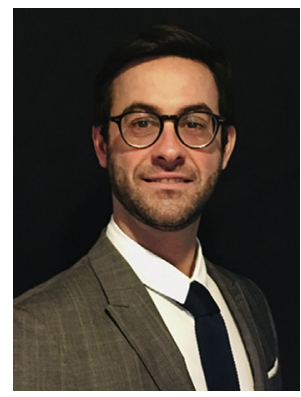

Benjamin Freychet, MD

Editors

Managing multiple ligament knee injury (MLKI) can be quite complex. Optimal treatment strategies are evolving but significant strides have been made with regards to surgical technique leading to improved patient reported outcomes. No two MLKIs are the same, and each patient requires an individualized approach. Controversies persist with regards to repair versus reconstruction of injured ligamentous structures, early versus late surgical management, and early versus delayed rehabilitation. Because these patients and their knee injury patterns are so heterogeneous in nature, it is difficult to perform high-level research to answer these highly debated questions.

In this issue of Clinics in Sports Medicine, we have brought together a group of international experts who have demonstrated a clinical interest and have published extensively in this field. Although level 1 randomized clinical trials are rare for this type of injury, level 5 evidence can actually provide significant insights into the optimal management of the MLKI.

The studies that have been compiled for this symposium focus on the importance of clinical diagnosis for ligament injury patterns, malalignment, meniscus, cartilage, and neurovascular injury. The authors present their preferred techniques for ACL and PCL reconstructions and MCL and LCL surgery, including when to repair and when to reconstruct. 
xvi Preface

This issue is addressed to orthopedic residents, fellows, and practicing surgeons searching for guidance on treatment of the MLKI based on the best available evidence in 2019.

Bruce A. Levy, MD

Department of Orthopedic Surgery and Sports Medicine

Mayo Clinic

200 First Street Southwest

Rochester, MN 55905, USA

Benjamin Freychet, MD

Department of Orthopedic Surgery and Sports Medicine

Mayo Clinic

200 First Street Southwest

Rochester, MN 55905, USA

E-mail addresses:

Levy.Bruce@mayo.edu (B.A. Levy)

benjamin.freychet@gmail.com (B. Freychet) 